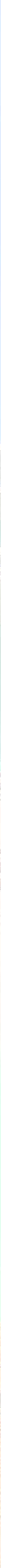




\title{
Museología
}

Una nueva casa para el

\section{tradicionista: la puesta en valor de la Casa Museo Ricardo Palma}

\author{
María Eugenia Yllia Miranda \\ Instituto de Investigaciones Museológicas y Artísticas \\ maria.yllia@urp.edu.pe \\ Lima- Perú \\ Vanesa Torres Bustamante \\ Investigadora Independiente \\ vanesatorresb@gmail.com \\ Lima-Perú
}

Anne Marie Acevedo Langschwager

Investigadora Independiente annemarie_acevedo@hotmail.com

Lima-Perú

\section{Resumen}

El artículo presenta el proceso de restauración arquitectónica y renovación museográfica de la Casa Museo Ricardo Palma, instalada en el espacio en donde pasó sus últimos años de vida el ilustre tradicionista. El proyecto fue considerado de prioridad por los vecinos de Miraflores e incluido en el presupuesto participativo 2016. El proceso abarcó la intervención estructural del inmueble, la elaboración de un guion curatorial y la propuesta de un diseño museográfico y gráfico novedoso y accesible, acorde a la tipología museológica de las casas museo y a las necesidades de los nuevos públicos.

Palabras clave: casa museo, Ricardo Palma, museografía, restauración de patrimonio, inmueble

\begin{abstract}
This article presents the process of architectural restoration and the museographic renovation of the Ricardo Palma House Museum, an entity created in 1969 in the district of Miraflores to make the public aware of the illustrious space traditionist spent last years of life. The residents of Miraflores considered the project as a priority in the 2016 participative budget, including different stages and interventions at a structural level and in the drafting of a new curatorial script presenting the dimension of the character through a renewed, modern and accessible museography following the typology of the museum houses.
\end{abstract}

Keywords: house museum, Ricardo Palma, museography, restoration of immovable heritage

\section{La creación de la Casa Museo Ricardo Palma}

En el marco de su compromiso por velar y promover la conservación y divulgación del arte y la cultura peruana, la Municipalidad de Miraflores emprendió en el año 2017, la tarea de poner en valor la última morada de Ricardo Palma Soriano (1833-1919), el hombre de letras más importante del siglo XIX e inicios del XX. Palma fue creador de la tradición, un género literario cuya originalidad suscitó seguidores en la narrativa hispanoamericana y que hasta hoy convoca el interés de investigadores de distintas latitudes.

El inmueble de la casa museo está ubicado en la esquina de las calles Belisario Suárez y Colina del distrito de Miraflores, fue construido en 1912 y alquilado por el tradicionista en 1913. Allí, junto a sus hijas, Palma pasó sus últimos seis años de vida. Luego de su muerte, la vivienda tuvo distintos usos hasta que, en 1962, fue declarado Monumento Histórico 
Nacional. El Museo y Centro de Estudios Ricardo Palma, como se llamó inicialmente, fue inaugurado el 6 de octubre de 1969, gracias a un conjunto de iniciativas encabezadas por Augusta Palma Román, hija del tradicionista, fallecida en 1963; el Frente de Cooperación Cívica de Miraflores y la Fundación Ricardo Palma ${ }^{1}$ que, conjuntamente con la Municipalidad de Miraflores, adquirieron el inmueble en 1967, bajo la condición de que solo fuera utilizada con ese fin. Para su funcionamiento, la Fundación Ricardo Palma y el Concejo Distrital de Miraflores redactaron un estatuto y reglamento de museo, y en 1968 se creó el Patronato de la Casa Museo Ricardo Palma, con la finalidad de que se haga cargo de su gestión.

\section{La necesidad de la puesta en valor de la Casa Museo Ricardo Palma}

Al ser un inmueble antiguo que había sido adaptado para otros usos, luego de un diagnóstico se concluyó que necesitaba un proyecto integral de puesta en valor, ya que su infraestructura se había deteriorado a través de los años. Desde el punto de vista museográfico, la Casa Museo Ricardo Palma no había actualizado su museografía ni la narrativa que presentaba sobre los espacios de la casa y el valioso legado del tradicionista, quedando prácticamente estática en el tiempo.

El legado que Ricardo Palma ha dejado al Perú tiene vigencia hasta la actualidad, y es motivo de múltiples estudios. Palma fue el creador de la tradición, un género narrativo que se nutre de fuentes escritas, como las crónicas, legajos y documentos, pero también de la memoria colectiva presente en la narrativa oral transmitida en las calles. Intelectual liberal y masón, Palma incursionó en política y fue uno de los nacionalistas más conspicuos de su generación, hecho demostrado en los distintos cargos que ejerció a lo largo de su vida. Fue oficial de la Marina de Guerra y reconstructor de la Biblioteca Nacional, además de ferviente patriota, esposo y padre ejemplar (Holguín, 2001).

La disposición que tenía la casa museo no presentaba la dimensión del legado de Palma y tampoco contaba con recursos educativos ni tecnologías que convierten a los museos en espacios multisensoriales abiertos a públicos cada vez más diversos. Es así que en el año 2016, durante la gestión de Crisia Málaga, Gerente de Cultura de la Municipalidad de Miraflores, y de Guillermo Guedes Ontaneda, director de la Casa Museo, el proyecto de recuperación del inmueble y la renovación de su museografía fueron considerados de prioridad en el presupuesto participativo 2016, gracias al interés de los vecinos. Un año después, en 2017, se iniciaron los estudios para su recuperación.

\section{La casa museo como tipología museológica}

En la primera etapa del proyecto fue indispensable conocer la naturaleza y problemáticas que afrontan las casas museo como tipología definida y estudiada en distintos contextos. Un primer punto de partida fue la tesis Propuesta de Plan Museológico para la Casa Museo Ricardo Palma (Yllia, 2016), en donde se hace un estudio de diversos textos y autores que analizan estas instituciones. Se trata de lugares de memoria que empezaron a proliferar en Europa desde el siglo XIX (Lorente, 1999). Concebidas originalmente como espacios de uso privado, como palacios reales, residencias, casas de personajes famosos, estudios de artistas, casas burguesas ricas e, incluso, cabañas modestas (Pinna, 2001), las casas museo, al patrimonializarse, se convierten en espacios públicos, hecho que define una de sus principales particularidades.

1 Sus creadores, Eugenio Alarco Larrabure, Luis Jaime Cisneros Vizquerra, Ricardo Palma Schamlz y Teresa García Salazar, cumplieron el encargo que les otorgó mediante testamento Augusta Palma Román, hija del tradicionista Ricardo Palma, fallecida el 18 de junio de 1963 (Alarco 2010). 
Las casas museo "tienen múltiples lecturas: espaciales, sociopolíticas, intelectuales, económicas, culturales" (Moreno, 2013, p. 215), pues en ellas se dan encuentro lo visible y lo invisible de la vida de un individuo. Estos temas no podían perderse de vista al momento de trabajar su puesta en valor. En estos museos se pone atención no solo en el valor de los objetos individuales, sino en todo el conjunto y su interacción con el espíritu de las personas que habitaron el espacio (Pinna, 2001). Estas prerrogativas plantean la necesidad de que su narrativa muestre un equilibrio en torno a cómo deber ser mostrada al público la vida pública y privada de un personaje (Yllia, 2016).

Como contenedor de un testimonio histórico que permiten un acercamiento retrospectivo a la privacidad del homenajeado (Lorente, 1999), la narrativa del nuevo guión museográfico de la Casa Museo Ricardo Palma, debía conjugar ambos aspectos y presentar el lado íntimo y familiar de un escritor de fama universal. Otro rasgo propio de estos museos es la naturaleza diversa e interdisciplinaria de sus colecciones, tema que complejiza no solo su conceptualización y orientación museológica, sino también su gestión y la conservación de sus acervos.

Las casas museo además de presentar el espacio de vida de un personaje, se transforman en lugares desde donde se piensa la importancia de su interpretación y su uso para fines educativos y didácticos (Pavoni, 2009). En ese sentido, la puesta en valor de la Casa Museo Ricardo Palma constituye una gran oportunidad para que la obra del tradicionista dialogue con las nuevas generaciones, ya que a través de ella se pueden establecer puentes entre la experiencia individual y la vasta y compleja red del saber -político, cultural, artístico, productivo-, y ofrecer al visitante el resultado de esta combinación, en la cual la micro y macrohistoria logran una narrativa eficaz (Pavoni, 2009).

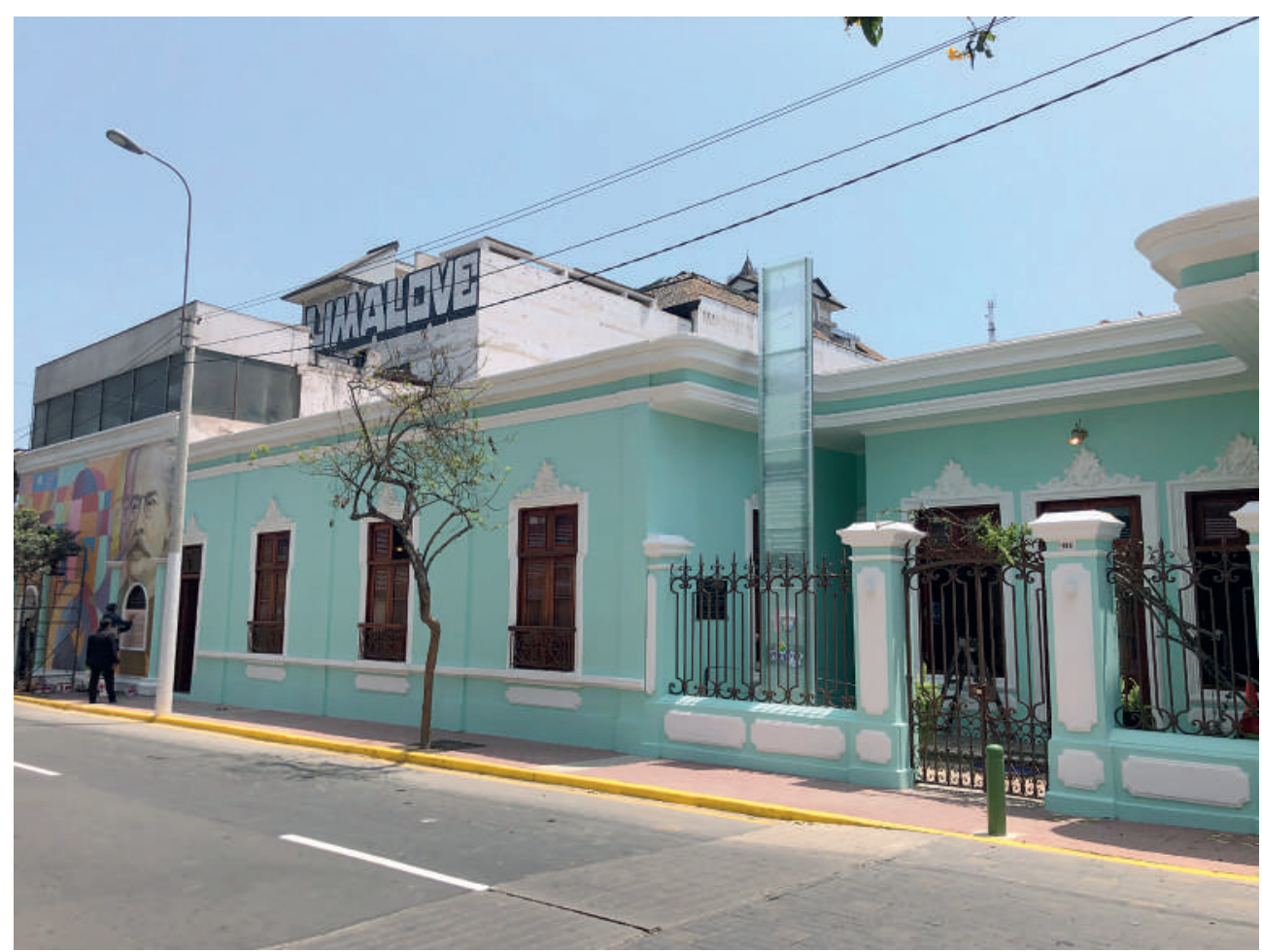

Fachada y tótem de ingreso. 


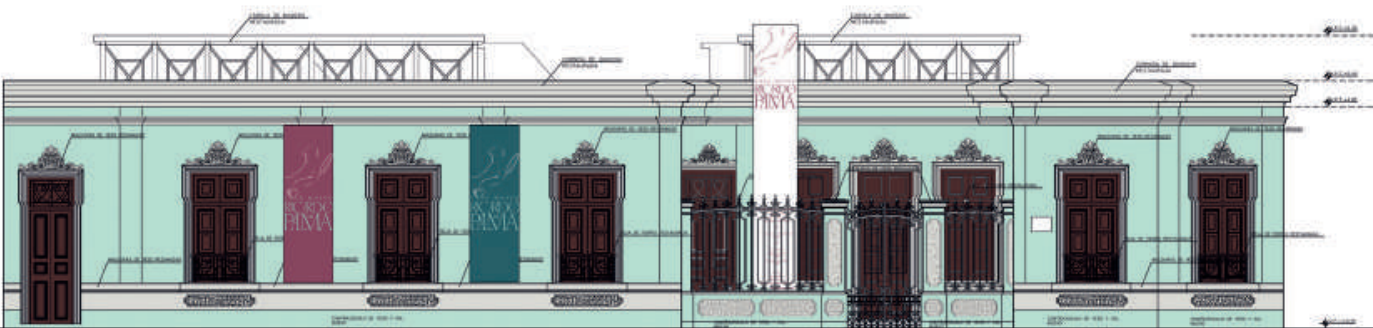

Propuesta de restauración fachada Casa Museo
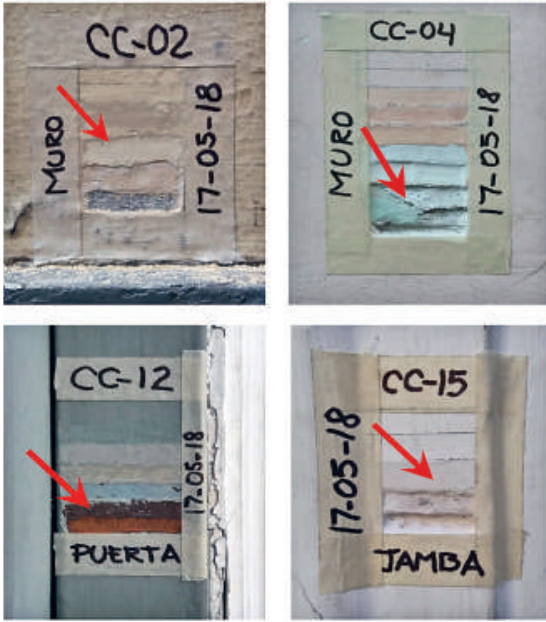

Calas y propuestas de color

\section{La importancia de contar con un equipo interdisciplinario}

$\mathrm{Al}$ ingresar en una casa museo se tiene la impresión de estar viendo la realidad exacta en la que el personaje habitó, no obstante, se trata de una realidad mediada por el trabajo conjunto de profesionales de distintas disciplinas. La responsabilidad de recuperar la historia y transmitirla a través del despliegue museológico es uno de los puntos que conlleva mayor reflexión entre los especialistas involucrados, ya que muchos de estos espacios suelen ser considerados sin cuestionamientos como lugares auténticos, y en ello radica el cautivante impacto que producen en el público (Risnicoff de Gorgas, 2001). Esta tarea compleja fue asumida por un equipo interdisciplinario conformado por arquitectos, ingenieros, museógrafos, curadores, historiadores, diseñadores, restauradores y gestores, que abordó el proyecto y estableció las distintas etapas del plan de trabajo (ver cuadro anexo).

\section{Arquitectura y conservación}

Al ser una edificación de inicios del siglo XX, la Casa Museo requirió de un arduo trabajo de conservación y restauración para poner en valor su infraestructura. Cabe destacar que se incorporaron a la propuesta de exhibición dos ambientes que no estaban habilitados al público y eran utilizados precariamente. A su vez, se adecuaron usos, creando un espacio para la recepción -tienda de la Casa Museo, un espacio de Biblioteca/Sala de exposiciones temporales- que complementan las salas de exhibición y el auditorio, consolidando un espacio cultural en toda su acepción. También se llevó a cabo el mejoramiento del patio principal, que cuenta con un simbólico árbol de floripondio al que se le dio un tratamiento para evitar que sus raíces afecten los pisos; además, se colocó un alcorque de acero para proteger el árbol y, a la vez, ampliar el área útil del patio.

A nivel de conservación arquitectónica, se detallan los principales componentes de intervención y las acciones que se tomaron para su recuperación.

Los muros de algunos ambientes se encontraban afectados por humedad, por lo que se evidenciaban fisuras superficiales. Se realizaron consolidaciones puntuales en los sectores donde las unidades de adobe se encontraban muy deterioradas. En intervenciones posteriores a la casa (la infraestructura albergó un colegio antes de convertirse en museo) se 

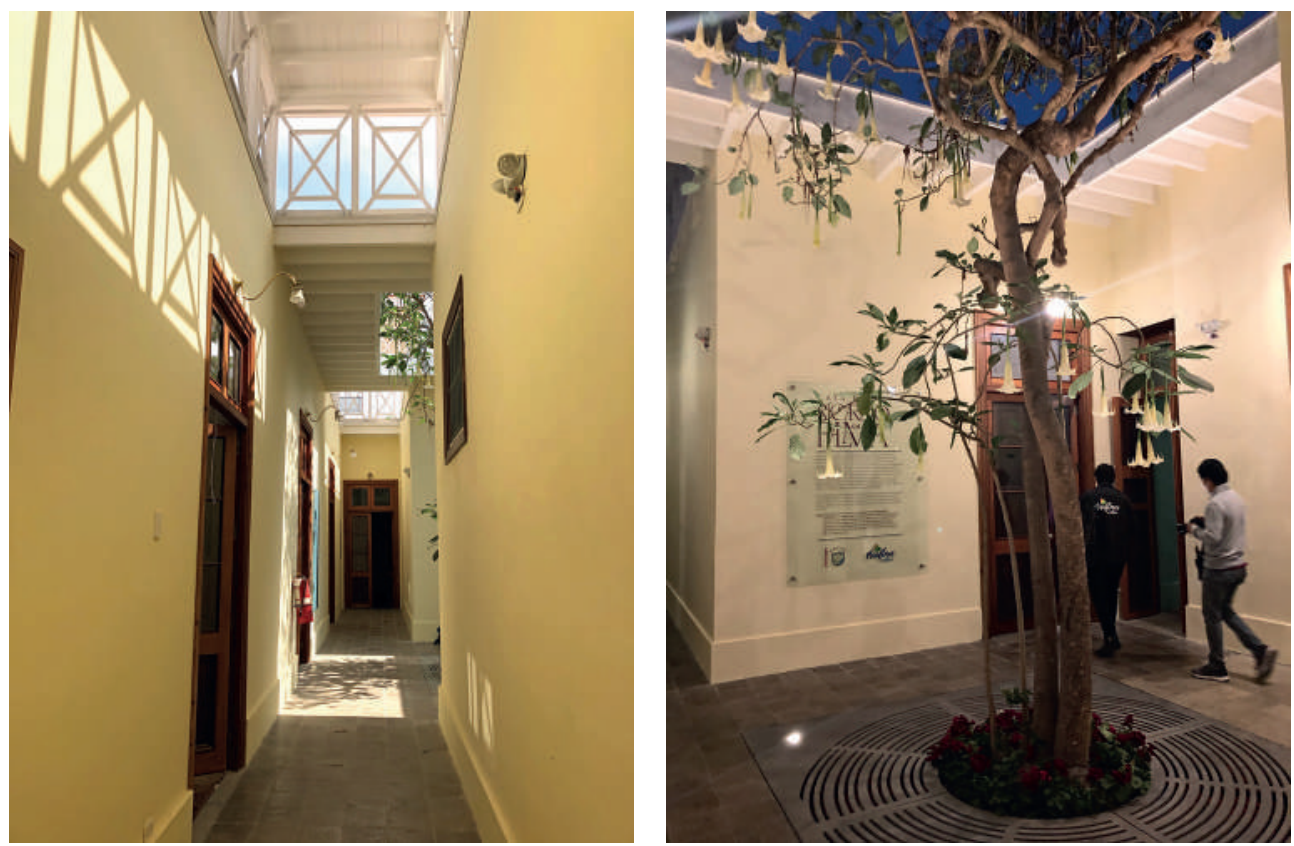

Ambientes restaurados y rehabilitados de la Casa Museo.

habían colocado zócalos de cemento en exteriores, que no permitían liberar la humedad contenida en muros, por ello, estos fueron reemplazados por zócalos de yeso. Los zócalos de madera, en su mayoría, fueron reemplazados, ya que se encontraban muy afectados por pudrición.

La estructura del techo está conformada por vigas y un entablado de madera que se encontraba afectado por insectos xilófagos y humedad. Aquellas vigas y tablas que habían perdido su capacidad estructural por las lesiones, fueron reemplazadas por piezas nuevas de similares características. La torta de barro fue reemplazada íntegramente por una nueva que se instaló sobre un manto asfáltico, que mantiene la madera impermeabilizada. La cornisa de fachada fue restaurada íntegramente.

La carpintería de madera se encontraba afectada por insectos xilófagos y otras lesiones de desgaste e impacto. Se propuso el proceso integral de restauración de cada elemento, que incluía el decapado de la pintura, el preservado del material, la reposición de piezas faltantes o muy dañadas y el acabado final con pintura óleo mate. Se consideró, asimismo, la reposición de una teatina nueva similar a las existentes en la zona de servicio que ya se había perdido totalmente. Las molduras de yeso y madera de jambas, alféizares y otros elementos fueron resanadas y conservadas. Se consideró la restitución de los pisos de madera en aquellos ambientes donde la madera era irrecuperable, así como la restauración del machihembrado de madera en ambientes menos afectados.

Se realizó también un estudio a través de estratigrafías de color en distintos elementos de la casa, como muros, carpintería de madera y metálica, molduras, etc., para encontrar los colores originales. La propuesta integral de color se elaboró de acuerdo con los resultados del estudio. Los ambientes principales fueron encontrados con papel tapiz -probablemente no el original-, y la propuesta consideró volver a tapizar esos mismos ambientes con diseños acordes a la época y estilo. 


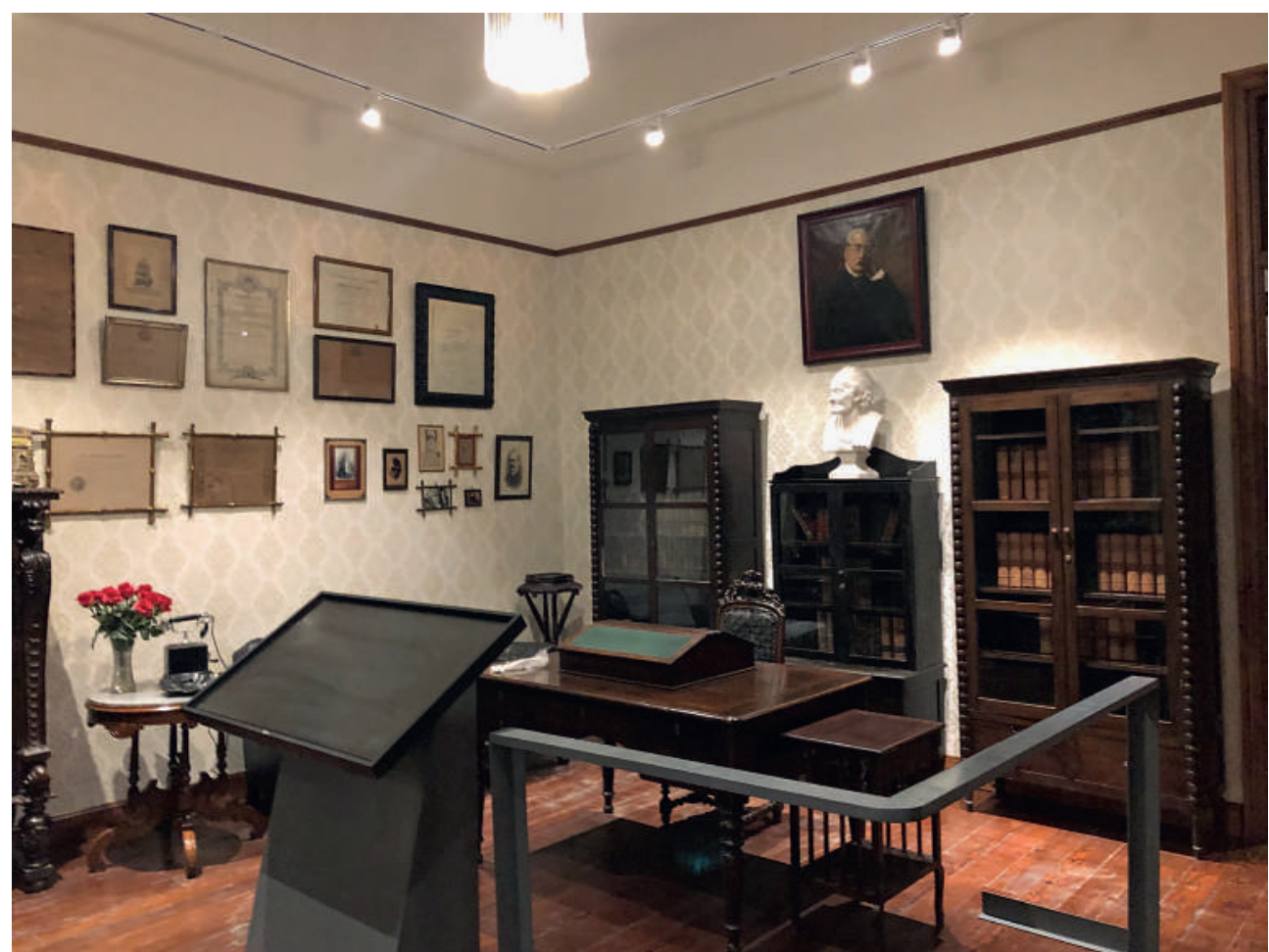

El despacho de Ricardo Palma.

Las tuberías de agua y desaguie fueron reemplazadas por nuevas y los baños han sido remodelados; se instaló un sistema de drenaje de aguas pluviales. Las instalaciones eléctricas fueron renovadas para la nueva iluminación y equipos, y también se incorporó un nuevo sistema de aire acondicionado.

\section{Propuesta curatorial y museografía}

El discurso museográfico de la Casa Museo Ricardo Palma no había tenido cambios sustantivos desde su inauguración, por lo tanto, era evidente que requería de un guion museográfico (Castrillón, 1986), documento guía que permitiría organizar y jerarquizar los contenidos. Aunque una de las metas de la exposición fue reconstruir, en la medida de lo posible, la apariencia que tenía la vivienda en la época en que fue ocupada por el insigne escritor, ello no siempre fue posible, debido a la falta de documentación existente. Sin embargo, las fotografías y el valioso acervo conformado por la biblioteca, pinacoteca, medallas, muebles, objetos personales del tradicionista y su familia, sirvieron de soporte para generar una narrativa, identificar temas y subtemas que permitan conocer más a fondo el personaje, su trayectoria de vida, las instituciones a las que perteneció, sus vínculos académicos, así como la importancia de su mayor legado: las tradiciones. En resumen, la propuesta partió de los siguientes lineamientos y objetivos:

Contribuir a la revalorización de la arquitectura original de la Casa Museo como tipologías de las residencias de inicios del siglo XX, destacando sus principales valores arquitectónicos.

Desarrollar un guion museográfico que contextualice los objetos museables y muebles de época, de acuerdo con la temática, y que destaque aspectos importantes de la vida y obra de Ricardo Palma. 
Plantear una propuesta novedosa que incorpore una nueva identidad gráfica para la Casa Museo, además de otros elementos de interpretación audiovisuales que contribuyan al mejor entendimiento de la vida y obra de Ricardo Palma y su importancia para el Perú de hoy.

La nueva propuesta curatorial y museográfica afrontó una serie desafíos. El primero debido a la inmensa cantidad de información que existe sobre el tradicionista, su vida familiar, actividades, cargos, obras, así como sus amistades a nivel mundial. Para ello, además de revisar las tradiciones y obras periodísticas y literarias de Palma, se llevó a cabo un proceso de documentación de las principales investigaciones dedicadas al estudio de la obra del tradicionista. Se contó también con las experiencias museográficas dedicadas al ilustre tradicionista realizadas por la Galería de Artes Visuales y el Instituto de Investigaciones Museológicas y Artísticas de la Universidad Ricardo Palma, que dirige el Dr. Alfonso Castrillón. El guion fue asesorado por el Dr. Alberto Varillas y por Guillermo Guedes Ontaneda, director de la Casa Museo Ricardo Palma.

Otro de los retos fue el de presentar a las nuevas generaciones a un personaje que transitó entre el siglo XIX y el XX. Para ello, desde el guion curatorial se planteó una museografía con diversos niveles de lectura, utilizando no solo un diseño innovador, sino también recursos didácticos, como animaciones de las tradiciones, entrevistas a investigadores y difusores de la obra del tradicionista, como Oswaldo Holguín Lavalle, Alberto Varillas Montenegro y Augusto Tamayo; además, se destinó un espacio interactivo para que el público pueda participar directamente, respondiendo a la pregunta: ¿Cuál es tu legado?

La propuesta fue concebida a partir de la conceptualización de las casas museo y su importancia como testimonio de la vida de un personaje ilustre para nuestra sociedad. A partir de ello, se conservaron los ambientes tal como fueron utilizados originalmente; estos son el escritorio de Ricardo Palma, la sala de música y el dormitorio del tradicionista. En ellos permanecen el mobiliario de época, así como pinturas, retratos, fotografías y otros objetos usados por la familia. En los ambientes que fueron recuperados se desarrolló una nueva propuesta curatorial y museográfica, que presenta las diversas facetas que tuvo Ricardo Palma, en especial su contribución al mundo cultural peruano. 


\section{Ejes temáticos del guion museográfico de la Casa Museo Ricardo Palma}

UNIDADES TEMÁTICAS

\begin{tabular}{|c|c|c|}
\hline Patio central & Introducción & $\begin{array}{l}\text { Presentación institucional (logos). Se destacará la importancia } \\
\text { de la casa como patrimonio. }\end{array}$ \\
\hline \multirow{2}{*}{ Sala I } & \multirow{2}{*}{$\begin{array}{l}\text { El escritorio del } \\
\text { tradicionista }\end{array}$} & $\begin{array}{l}\text { El espacio, sus usos y los personajes ilustres que lo } \\
\text { frecuentaron. }\end{array}$ \\
\hline & & $\begin{array}{l}\text { Touch screen. Se describirán los bienes más importantes de } \\
\text { este ambiente. }\end{array}$ \\
\hline \multirow[b]{2}{*}{ Sala II } & \multirow[b]{2}{*}{ Palma y su familia } & Ricardo Palma y su familia. \\
\hline & & $\begin{array}{l}\text { La sala de música, espacio de exhibición de las obras de Reneé } \\
\text { Palma. }\end{array}$ \\
\hline \multirow{8}{*}{ Sala III } & \multirow{8}{*}{ La vida múltiple } & $\begin{array}{l}\text { Los primeros años de una vida ejemplar. La generación de los } \\
\text { bohemios. }\end{array}$ \\
\hline & & Palma y la Marina de Guerra. \\
\hline & & $\begin{array}{l}\text { La vida política de Palma. La intelectualidad de fines del siglo } \\
\text { XIX y la construcción de la Nación. }\end{array}$ \\
\hline & & Objetos personales del tradicionista \\
\hline & & Homenajes y reconocimientos a su trayectoria. \\
\hline & & Tello y Palma. \\
\hline & & Manuel Piqueras Cotolí. \\
\hline & & $\begin{array}{l}\text { Palma como gestor de la Biblioteca Nacional. El bibliotecario } \\
\text { mendigo. }\end{array}$ \\
\hline \multirow{7}{*}{ Sala IV } & \multirow{7}{*}{$\begin{array}{l}\text { Las Tradiciones } \\
\quad \text { Peruanas }\end{array}$} & ¿Qué es la tradición? Características. \\
\hline & & “El pueblo me lo contó y yo al pueblo se lo cuento". \\
\hline & & $\begin{array}{l}\text { Piqueras Cotolí. Dibujos y esculturas dedicadas a Palma y a su } \\
\text { obra. }\end{array}$ \\
\hline & & Teófilo Castillo. \\
\hline & & Pancho Fierro. Reproducción de acuarelas. \\
\hline & & Video: animación de tres tradiciones. \\
\hline & & $\begin{array}{l}\text { Ilustraciones de las Tradiciones de Palma: Fernando Marco, } \\
\text { Carlos Quizpez Asín, Raúl Vizcarra, Apurimak. }\end{array}$ \\
\hline \multirow{5}{*}{ Sala V } & \multirow{5}{*}{ Palma y su legado } & El legado de Palma para el Perú y el mundo. \\
\hline & & $\begin{array}{l}\text { Video de entrevistas a personalidades que comentan la } \\
\text { importancia de Palma: Oswaldo Holguín Lavalle, Alberto } \\
\text { Varillas Montenegro, Augusto Tamayo. }\end{array}$ \\
\hline & & Palma retratado por los ilustradores de la época. \\
\hline & & $\begin{array}{l}\text { Vitrina con obras literarias de Palma y ediciones en distintos } \\
\text { idiomas. }\end{array}$ \\
\hline & & Clemente Palma y las revistas ilustradas / Angélica Palma \\
\hline
\end{tabular}




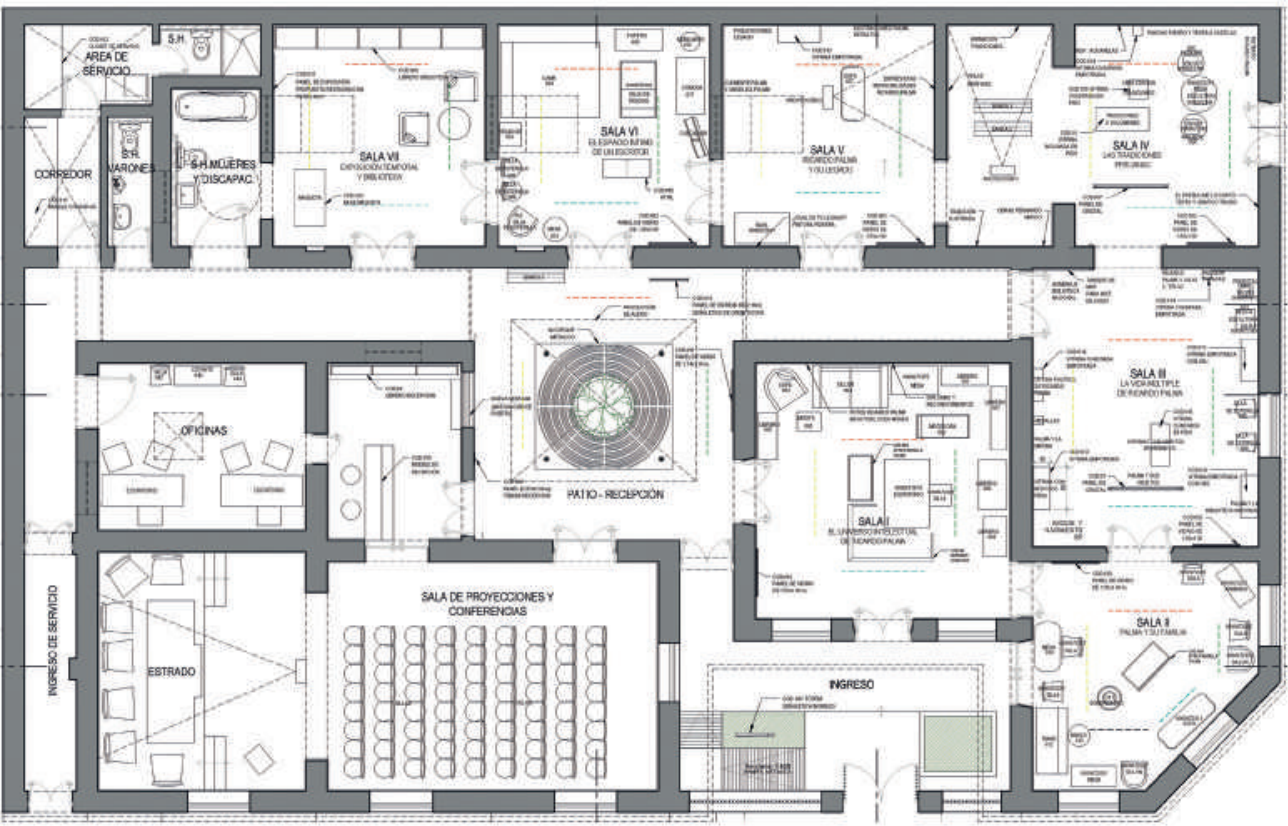

Planta de distribución y museografía Casa Museo Ricardo Palma.

La nueva museografía de la Casa Museo Ricardo Palma

Para respetar y devolver el aura de los espacios "históricos", la propuesta museográfica formuló elementos que no los disturbaran. Los espacios recuperados fueron intervenidos en su totalidad con un diseño museográfico y gráfico más versátil y dinámico, siempre acorde con la particularidad del personaje y la naturaleza del museo. Esta tarea contempló los siguientes lineamientos y dispositivos museográficos:

- Tótem-señalética de ingreso, a través de una estructura traslúcida que identifica la Casa Museo y se integra con la fachada.

- Paneles de cristal utilizados como paneles de introducción en cada sala con un soporte que no afecte la visual de la arquitectura de la Casa.

- Vitrinas exentas y adosadas a los muros, que permitan destacar adecuadamente los objetos relacionados con la vida y obra de Ricardo Palma.

- Atriles complementarios con pantallas táctiles presentando información detallada sobre la colección.

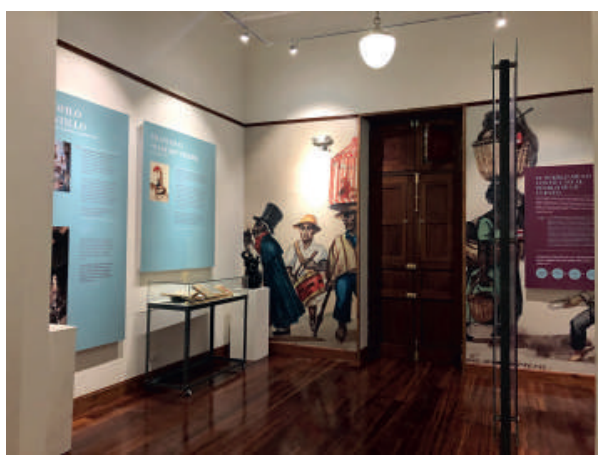


- Proyecciones: tradiciones animadas en la Sala de las Tradiciones y testimonios de principales palmistas sobre el legado de Palma.

- Iluminación puntual a través de rieles y proyectores LED en todos los ambientes, que brinden iluminación de acento a los diversos objetos museográficos expuestos en cada sala. La iluminación original (luminarias colgantes de época) existente permanece como iluminación complementaria en cada sala.

- Restauración de los bienes muebles considerados como patrimonio mueble por el Ministerio de Cultura.

- Nueva propuesta de identidad gráfica, que incluye un nuevo logo basado en uno de los retratos de Palma; paleta de colores pasteles en base a cromática de casa y algunos elementos pictóricos de la colección. También se propuso una tipografía.

\section{El futuro de la Casa Museo}

La gestión de la Casa Museo Ricardo Palma afronta importantes desafíos. El primero de ellos es realizar un plan estratégico a corto plazo, que defina sus futuras acciones y objetivos como institución viva y dinámica.

Entre las tareas más urgentes están las de implementar programas educativos que acerquen al público diversos recorridos inclusivos que tengan en cuenta la accesibilidad. La mediación es fundamental para complementar y hacer óptima la visita a este espacio de memoria.La puesta en valor de la Casa Museo Ricardo Palma es un importante testimonio del interés de los vecinos, quienes participaron directamente en la elección de la prioridad de financiar el proyecto, por lo que deben ser considerados como una parte activa del museo.

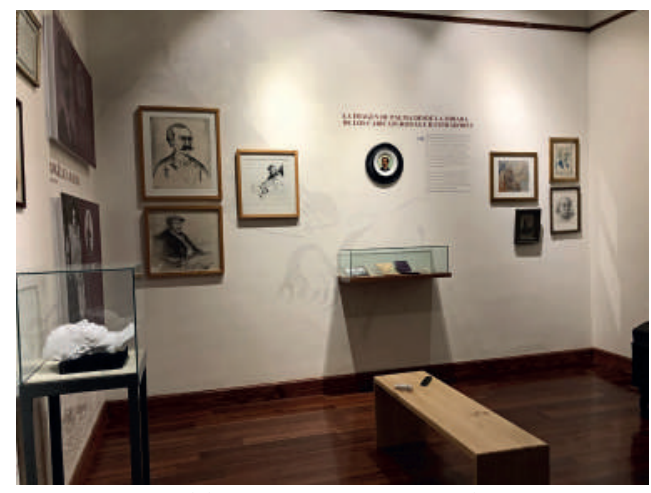

Sala Las Tradiciones / Sala El Legado de Ricardo Palma.

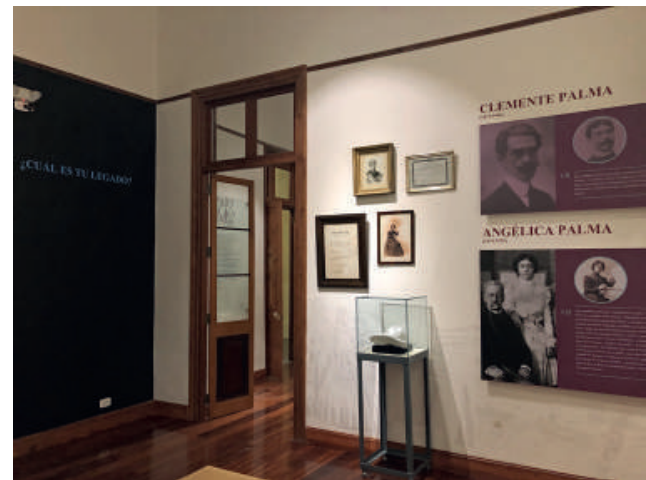

Sala el Legado de Ricardo Palma.

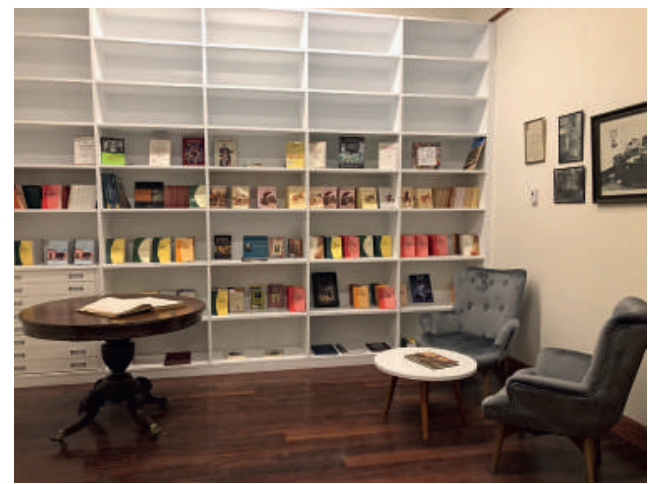

Sala Las Tradiciones / Sala el Legado de Ricardo Palma. 


\section{Créditos de Proyecto de puesta en valor}

Adecuación arquitectónica:

Vanesa Torres Bustamante, Anne Marie Acevedo

Langschwager

Conservación y restauración arquitectónica:

Anne Marie Acevedo

Langschwager

Ingenierías:

José Caytuiro Sandoval,

Gabriel Zeña Muñoz,

Carmen De la Cruz Aliaga

Curaduría y guion

museográfico:

Maria Eugenia Yllia Miranda,

Kelly Carpio Ochoa, Patricia

Mondoñedo

Museografía:

Vanesa Torres Bustamante

Diseño gráfico:

Carlos Rojas Pérez

Restauración de bienes muebles:

Kullasiri, José Alberto

Christiansen Chu Chimpecan

Fotografías del artículo:

Vanesa Torres Bustamante
Ejecución de obra e

implementación:

Municipalidad de Miraflores

Municipalidad de Miraflores:

Alcalde Luis Molina Arles

Gerentes de Cultura y Turismo:

Crisia Málaga Newton,

Roberto Boyle, María Elena

Herrera, Gonzalo Iwasaki y

Miguel Molinari Portal

Director Casa Museo Ricardo

Palma:

Guillermo Guedes Ontaneda

Personal de la Casa Museo

Ricardo Palma

Sofía Cervantes y Jorge

Huamán

Agradecimientos

Biblioteca Nacional del Perú:

Gerardo Manuel Trillo, Laura

Martínez, Margarita Roel

Mendizábal

Ministerio de Cultura:

Gerardo Moreno Arias

Alberto Varillas Montenegro, Alfonso Castrillón Vizcarra

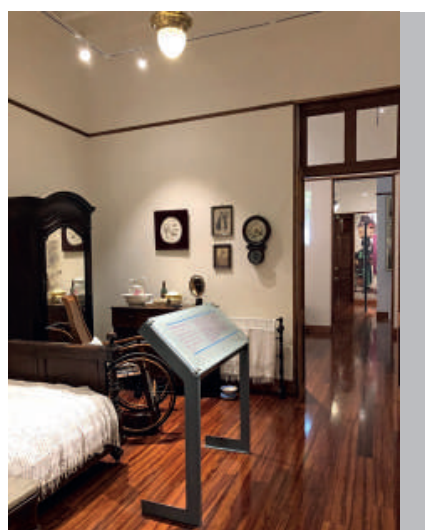

El dormitorio de Ricardo Palma.

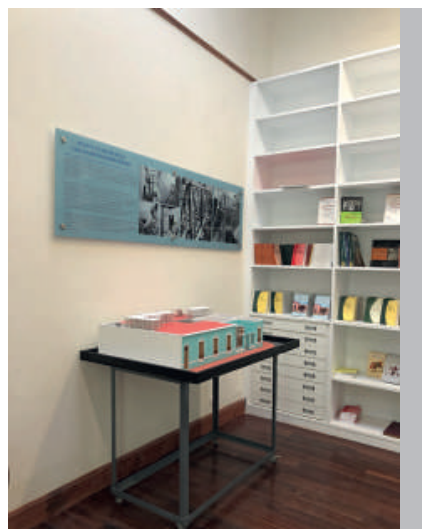

\section{Referencias bibliográficas}

Alarco, E. (2010). La casa museo de Ricardo Palma. Lima: Fundación Ricardo Palma.

Castrillón, A. (1986). Museo peruano: utopía y realidad. Lima: Industrial Gráfica.

Holguín, O. (2001). Páginas sobre Ricardo Palma. (Vida y obra). Lima: Universidad Ricardo Palma. Editorial Universitaria.

Lorente, J. (1999). “¿Qué es una Casa-Museo? ¿Por qué hay tantas Casas-Museo decimonónicas?" En: Revista de Museología, 14, junio, pp. 30-32. Editorial TEM.

Pavoni, R. (2009). "Casas Museo: perspectivas para un nuevo rol en la cultura y la sociedad". En: Illapa mana tukukuq N. ${ }^{\circ}$ 6, pp. 109-108. Lima: Instituto de Investigaciones Museológicas y Artísticas - URP.

Pavoni, R. (2012). Casa Museo. Una tipología para poner en valor. Recuperado: http://network.icom.museum/fileadmin/ user_upload/minisites/icomargentina/pdf/ casas_museos_es.pdf
Pavoni, R. (2013). "Casas museo: perspectivas para un nuevo rol en la cultura y en la Sociedad”. En: Casas museo: museología y gestión. Actas de los Congresos sobre Casa Museo (2006, 2007, 2008), pp. 241-251. Museo de Educación, Cultura y Deporte.

Pinna, G. (2001). "Introduction to historic house museum". En: Museum International, vol. 53, Issue 2, Unesco. Recuperado de: https://doi.org/10.1111/1468-0033-00306

Risnicoff de Gorgas, M. (2001). Reality as illusion, the historic houses that become Museums. En: Museum International 210(53) 2, pp. 10-15. Unesco.

Yllia, M. E. (2016). Propuesta de plan museológico para la Casa Museo Ricardo Palma [tesis para optar el grado de Maestra en Museología y Gestión Cultural, Universidad Ricardo Palma].

Recibida el 29 de septiembre de 2020 Aceptada el 19 de octubre de 2020 